\title{
Hydraulic size of non-spherical solid particles
}

\author{
Liudmila Volgina* and Anastasiia Romanova
}

Moscow State University of Civil Engineering, Yaroslavskoe shosse, 26, Moscow, 129337, Russia

\begin{abstract}
The paper studies impact of determining the diameter of solid particles on the calculation of the hydraulic particle size in the water flow. The relevance of the topic is also connected with the use of calculation of hydraulic size in hydraulic engineering in forecasting: downstream erosion, the formation of shoals, canals, bottom spillages, etc. Most of the empirical formulas for calculating the hydraulic particle size are applicable to spherical particles. However, the nature of the solid particles rarely has a spherical shape. The aim of this work is to investigate experimentally the dependence of the hydraulic size of the diameter of the solid particles. Different approaches to determining the diameter solid particles are analyzed, as for non-spherical particles finding the diameter is an independent and complex problem. For the experimental research solid particles of different shapes and sizes were used. The diameter is included in the empirical formulas for hydraulic size linearly, and to the power of 2 or 0.5 . Therefore, the dependence of the experimental hydraulic size on the diameter was correlated with the corresponding functions. The shape of the particle significantly affects the value of the hydraulic size and depends on the diameter to the power of (0.5).
\end{abstract}

\section{Introduction}

The aim of the work is an experimental study of the dependence of the hydraulic size on the particle diameter, the shape of which differs from spherical. Hydraulic particle size (particle velocity) is included in the basic calculation formulas to determine the permissible (critical, non-silting) velocities and the distribution of solid particles in the depth of the flow.

The parameters of motion of a solid particle, the shape of which is different from the spherical, differ from the parameters of motion in the flow of spherical particles.

Hydraulic particle size is one of the main parameters of semi-empirical equations of turbulent diffusion, is an input parameter to simulate the dynamics of suspended particles in any flow [1]. Moreover, the calculation of hydraulic size is important not only at the stage of construction and design, but also in the further operation of hydraulic constructions.

The hydraulic size, (velocity of the particles) according to the definition, is the rate of uniform precipitation of solid particles in a stationary fluid $[\omega]=\mathrm{m} / \mathrm{sec}$. Theoretically, the problem of precipitation of spherical-shaped particles was solved by the English scientist $\mathbf{J}$ $\mathrm{G}$ Stokes, which got the dependence of the resistance force $\mathrm{Fc}$ on the hydraulic size:

$$
F_{c}=3 \cdot \pi \cdot \varpi \cdot \mu \cdot d
$$

where: $\quad d-$ average particle diameter, $m$;

$$
\mu \text { - the dynamic coefficient of water viscosity, } \mathrm{kg} \cdot \mathrm{sec} / \mathrm{m}^{2} \text {. }
$$

\footnotetext{
${ }^{*}$ Corresponding author: VolginaLV@ gic.mgsu.ru
} 
The resistance force varies in proportion to the velocity, i.e. linearly. Stokes' law is valid for very small particles precipitating with low velocity (laminar flow), when only viscous forces affect motion resistance. With an increase in the size and deposition rate of particles, the linear law will change. This is due to the occurrence of turbulence in the flow of particles around solid particles. There are three types of deposition - laminar, transient and turbulent. For the turbulent flow regime, a quadratic law of resistance is characteristic (such a regime is observed during the deposition of particles whose diameter $>3-5 \mathrm{~mm}$ ).

Currently, the actual problem [2,3] is the question of choosing a formula for calculating the hydraulic size or method that is a combination of empirical and theoretical estimates. As noted in modern literature, in most cases, the problem of choice arises with a fairly wide range of particle diameters and various types of particle size distribution.

\section{Methods}

The method of research is experimental, during which solid particles were selected on the principle of the greatest difference in shape from spherical. Solid particles of different shapes, masses and densities were used.

Solid particles feature of the motion dependent on the degree of roundness and absolute geometric size. Roundness is non spherical shape particles characteristic. Solid particles can have spherical, flat, roundness, non-roundness shapes. Geometric size is linear size (dimension), diameter or cross-section length. The calculation of the diameter of a spherical solid particle causes no doubts, but for particles whose shape is different from spherical, there are several different methods for determining the diameter:

- determination of the diameter through the volume of an equal sphere:

$$
d=\sqrt[3]{\frac{6 V}{\pi}}
$$

- determination of the diameter of the weight of an equal sphere. In this case, the volume is then calculated using the weight and density; then, it is calculated using the formula 2 ;

- determination based on the surface area of the particle (taken as the area of an equal sphere):

$$
d=\sqrt{\frac{S}{\pi}}
$$

- determination of the average diameter across the width, height and length of the maximum (mid-section of the particle), according to the Goncharov Karaushev formula [4]:

$$
d=\frac{L+B+M}{3}
$$

Experiments and calculations show that for particles other than a sphere, the diameter calculation method gives a large scatter of data [5].

To determine the effect of the diameter of a solid particle of various shapes on the hydraulic size in the laboratory of the Department of Hydraulics and Hydrotechnical engineering of Moscow State University of Civil Engineering (from 2016 to 2019), experiments were conducted, the main purpose of which was to determine the characteristics of the fall of various particles in the fluid flow for further analysis of the hydraulic particle size of solid particles. 
Hydraulic size, in essence, is the velocity of a particle in a fluid. To calculate this parameter experimentally, the formula 5 is used.

$$
\omega=\frac{L}{t}
$$

where: $\mathrm{L}-$ distance traveled between river beds;

$\mathrm{t}$ - travel time.

The following equipment was used in the experiments:

- test flask (Fig. 1);

- stopwatch;

- scales;

- beaker.

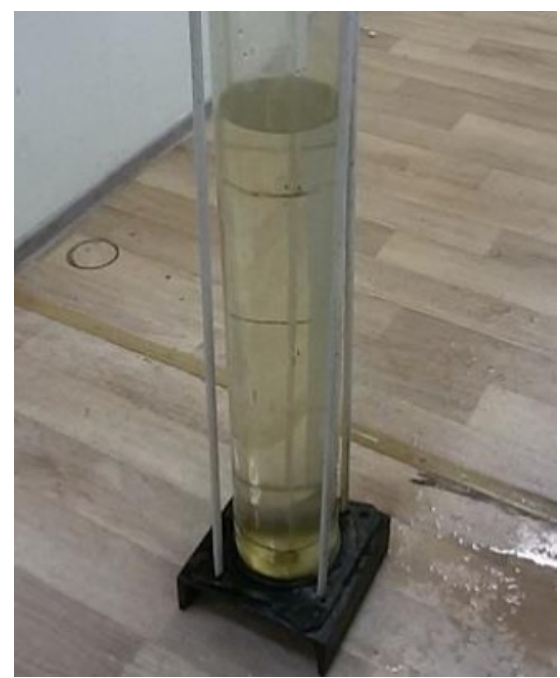

Fig. 1. Test flask

Experiment description:

- For the experiment, tap water was chosen as the liquid, which was filled with an experimental flask to a level exceeding the length of the measured distance;

- $\quad$ selected particles of different material and different shapes (

- Table 1) were dropped into the flask;

- during a free fall of a particle, the beginning of the measuring section was chosen at a distance from the surface (stabilization zone) since the free fall velocity is uneven in this section;

- the time for the particle to pass through the measuring section was recorded using a stopwatch;

- according to the formula (5), the value of the falling velocity particle was calculated;

- for particles with known composition and density, weight was measured and volume was calculated. For particles of non-uniform composition, the volume was determined by immersing the particle in a flask;

- according to the method of determining the particle diameter, the diameter was determined for each particle (2). 
Table 1. Characteristics of experimental particles

\begin{tabular}{|c|c|c|c|c|}
\hline $\begin{array}{c}\text { Experiment } \\
\text { group }\end{array}$ & $\begin{array}{c}\text { Num } \\
\text { ber of } \\
\text { parts }\end{array}$ & $\begin{array}{c}\text { Particle } \\
\text { configuration }\end{array}$ & $\begin{array}{c}\text { Particle } \\
\text { material }\end{array}$ & Notes \\
\hline 1 & 5 & polygon & glass & - \\
\hline 2 & 12 & polygon & glass & standard - coin \\
\cline { 2 - 5 } & 4 & cylinder & metal & larger and smaller section \\
\hline 3 & 15 & polygon & glass & larger and smaller section \\
\hline 4 & 15 & polygon & rocks & $\begin{array}{c}\text { standard - coin larger and } \\
\text { smaller section }\end{array}$ \\
\hline 5 & 4 & cylinder & metal & different diameter \\
\hline 6 & 9 & spherical & different & $\begin{array}{c}\text { glass / } \\
\text { plastic }\end{array}$ \\
\hline 7 & 6 & polygon & plastic + & $\begin{array}{c}\text { different surface roughness for } \\
\text { sand }\end{array}$ \\
\hline 8 & 4 & spherical & particle \\
\hline
\end{tabular}

In the process of the experiments, solid particles of different shapes, masses and densities were used (Table 2). Hydraulic sizes of more than 100 solid particles were measured in the laboratory. Figures 2-6 show some example of experimental particles.

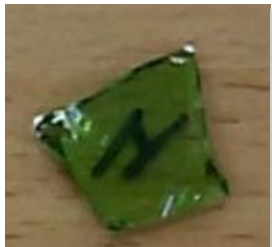

Fig. 2. Series 3

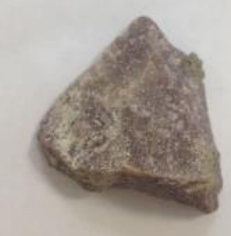

Fig. 3. Series 4

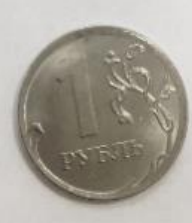

Fig. 4. Series 5

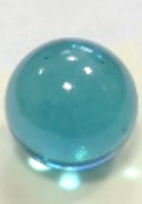

Fig. 5. Series 6

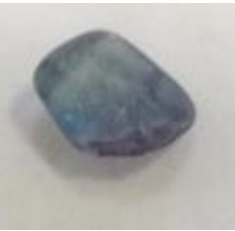

Fig. 6. Series 7

\section{Results}

Particle diameter is the main parameter (since the term hydraulic size also comes from it). Most of the formulas are used in the calculation of the reference particles of spherical shape, and experiments are carried out mainly to obtain data of spherical particles. In real conditions, the shape of particles is rarely spherical and this can greatly affect the velocity of a particle.

Solid particles feature of the motion dependent on the degree of roundness and absolute geometric size. Roundness is non spherical shape particles characteristic. Solid particles can have spherical, flat, polygon, cylinder, roundness, non-roundness shapes. Geometric size is linear size (dimension), diameter or cross-section length.

Diameter was calculated using formula (2), (3) and (4). Table 2 shows the results of calculations for the table presents the results of 3 group experiment.

Table 2. Particle shape characteristics of 3 group experiment

\begin{tabular}{|c|c|c|c|c|c|c|c|}
\hline Symbol & $\mathrm{S}$ & $\mathrm{d}_{\mathrm{s}}$ & $\mathrm{m}$ & $\mathrm{V}$ & $\mathrm{d}_{\mathrm{w}}$ & $\mathrm{d}_{\mathrm{a}}$ & $\mathrm{f}$ \\
\hline name & $\begin{array}{c}\text { surface } \\
\text { area }\end{array}$ & $\begin{array}{c}\text { diameter } \\
\text { by } \\
\text { surface }\end{array}$ & weight & volume & $\begin{array}{c}\text { diameter } \\
\text { by } \\
\text { volume }\end{array}$ & $\begin{array}{c}\text { average } \\
\text { diameter }\end{array}$ & $\begin{array}{c}\text { shape } \\
\text { parameter }\end{array}$ \\
\hline
\end{tabular}




\begin{tabular}{|c|c|c|c|c|c|c|c|}
\hline dimension & $\mathrm{mm}^{2}$ & $\mathrm{~mm}$ & $\mathrm{~g}$ & $\mathrm{~cm}^{3}$ & $\mathrm{~mm}$ & $\mathrm{~mm}$ & - \\
\hline 1 & 325 & 10,17 & 0,58 & 0,23 & 7,62 & 10,67 & 1,87 \\
\hline 2 & 98 & 5,59 & 0,17 & 0,07 & 5,06 & 5,67 & 1,23 \\
\hline 3 & 88 & 5,29 & 0,26 & 0,10 & 5,84 & 5,00 & 0,78 \\
\hline 4 & 386 & 11,09 & 0,6 & 0,24 & 7,71 & 9,67 & 1,82 \\
\hline 5 & 102 & 5,70 & 0,23 & 0,09 & 5,60 & 4,67 & 0,86 \\
\hline 6 & 150 & 6,91 & 0,34 & 0,14 & 6,38 & 6,00 & 1,03 \\
\hline 7 & 148 & 6,87 & 0,32 & 0,13 & 6,25 & 6,00 & 1,06 \\
\hline 8 & 304 & 9,84 & 0,71 & 0,28 & 8,16 & 8,00 & 1,21 \\
\hline 9 & 110 & 5,92 & 0,21 & 0,08 & 5,43 & 6,00 & 1,20 \\
\hline 10 & 140 & 6,68 & 0,19 & 0,08 & 5,26 & 6,17 & 1,50 \\
\hline 11 & 106 & 5,81 & 0,16 & 0,06 & 4,96 & 4,67 & 1,13 \\
\hline 12 & 261 & 9,12 & 0,46 & 0,18 & 7,06 & 7,33 & 1,37 \\
\hline 13 & 82 & 5,11 & 0,16 & 0,06 & 4,96 & 4,00 & 0,85 \\
\hline 14 & 80 & 5,05 & 0,14 & 0,06 & 4,75 & 5,00 & 1,12 \\
\hline 15 & 134 & 6,53 & 0,21 & 0,08 & 5,43 & 5,67 & 1,27 \\
\hline
\end{tabular}

Calculations show that for particles diameter calculation method gives a large spread of data, more detail, see [5]. The influence of the shape of the particles can be characterized by the parameter [6]:

$$
f=\left(d_{s} / d_{w}\right)^{2} \text { or } f=\left(d_{a} / d_{w}\right)^{2}
$$

where: $d_{s}, d_{a}, d_{\omega}$ - the diameters of the sphere, which is equivalent to the particle by the surface, the average diameter and volume.

The dependence of the shape parameter $f$ of the particle diameter $d_{a}, d_{s}$ and $d_{w}$ shows wide spread calculated diameter (Fig. 7).

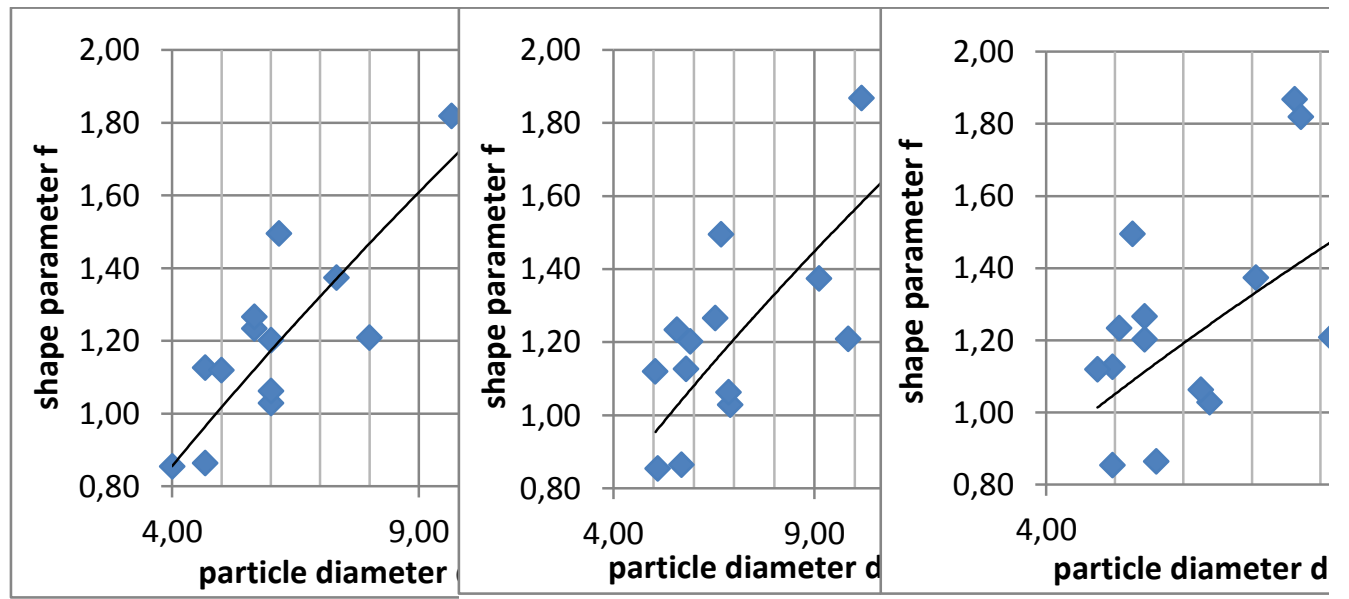

Fig. 7. Shape parameter and solid particles geometric size

The advantage to determine the particle diameter by weight with the necessary accuracy is simplicity. In order, to achieving the required accuracy recommended use diameter as:

$$
d=f d_{w}
$$

In the quality of the final parameter $f$ in this work, the arithmetic average value is taken. 


\section{Discussion}

Formulas for calculating the hydraulic size offered by many authors on the based on theoretical and experimental studies. An overview of the empirical dependencies for calculating the hydraulic size proposed by various authors is presented below [7].

1. Theoretical formula of British mathematics Navie-Stokes, suitable for laminar flow at Reynolds numbers $\mathrm{Re} \leq 1$, suitable for small particles, for example, sludge:

$$
\omega=\frac{2 \cdot g \cdot r^{2} \cdot\left(\rho_{\mathrm{T}}-\rho\right)}{9 \cdot \mu}
$$

where: $\quad \mathrm{r}[\mathrm{mm}]$ - radius of the particle;

$\rho_{\mathrm{T}}, \rho\left[\mathrm{g} / \mathrm{cm}^{3}\right]$ - the density of solid particles or water;

$\mu$ - the dynamic coefficient of water viscosity;

$\mathrm{g}\left[\mathrm{m} / \mathrm{s}^{2}\right]$ is the acceleration due to gravity.

2. The following formula is represented by Allen applied to a turbulent flow and has the greatest convergence for large solid particles:

$$
\omega=\frac{25,8 \cdot d \sqrt[3]{(\delta-1)^{2}}}{\sqrt[3]{\mu}}
$$

where: $\quad \mathrm{d}[\mathrm{mm}]$ - particle diameter;

$\delta$ - relative density;

$\delta=\rho_{\mathrm{T}} / \rho$.

3. Rettinger proposed a formula for the transition region of these types of flow. It works with medium-sized particles:

$$
\omega=k_{\rho} \sqrt{d \cdot(\delta-1)}
$$

where: $\quad k_{\rho}$ - dimensionless shape coefficient.

The dimensionless shape coefficient is experimentally determined for particles in water: spherical $=2.73$, oblong -2.97 , flat -1.97 .

4. A universal method for determining the hydraulic particle size proposed by Ruby:

$$
\omega=F \sqrt{d g \frac{\left(\rho_{\mathrm{T}}-\rho\right)}{\rho},}
$$

where: F - a correction factor that takes into account the shape of the particles and is determined according to the formula:

$$
F=\sqrt{\frac{2}{3}+\frac{36 \cdot \mu^{2}}{g \cdot d \cdot \rho \cdot\left(\rho_{\mathrm{T}}-\rho\right)}}
$$

5. Another Navie - Stokes formula for which there is no data limitation:

$$
\omega=\sqrt{\frac{\gamma_{\mathrm{T}}-\gamma}{24 \cdot \mu} \cdot \mathrm{d}^{2}},
$$

where: $\quad \gamma_{\mathrm{T}}, \gamma\left[\mathrm{kg} / \mathrm{m}^{3}\right]-$ the specific weight of a particle or water.

6. For calculation in hydrotransport, Goncharov-Karaushev suggests using the following relation to determine the velocity of a particle in a fluid: 


$$
\omega=1,37 \sqrt{\frac{\left(\rho_{\mathrm{T}}-\rho\right)}{\rho} \cdot g \cdot d_{a}\left(\frac{L \cdot B}{d}\right)^{0,9}},
$$

where: $\quad d_{c p}[\mathrm{MM}]$ - average particle diameter.

7. In reference [8] found the formula:

$$
\omega=\sqrt{g \cdot d \cdot \frac{4}{3 \cdot C_{D}} \cdot \frac{\rho_{T}-\rho}{\rho}}
$$

where: $\quad \mathrm{C}_{\mathrm{D}}-$ the flow coefficient.

These criteria also need to be considered, since the flow around particles of various shapes occurs in different ways (Fig. 8).

8. It is also common to find a formula that has limitations of applicability for particles of $d>1.5 \mathrm{~mm}$ and for Reynolds numbers $\mathrm{Re} \geq 240$ :

$$
\omega=\sqrt{\frac{2 \cdot g \cdot\left(\gamma_{\mathrm{T}}-\gamma\right) \cdot \mathrm{d}}{1.75 \cdot \gamma}}
$$

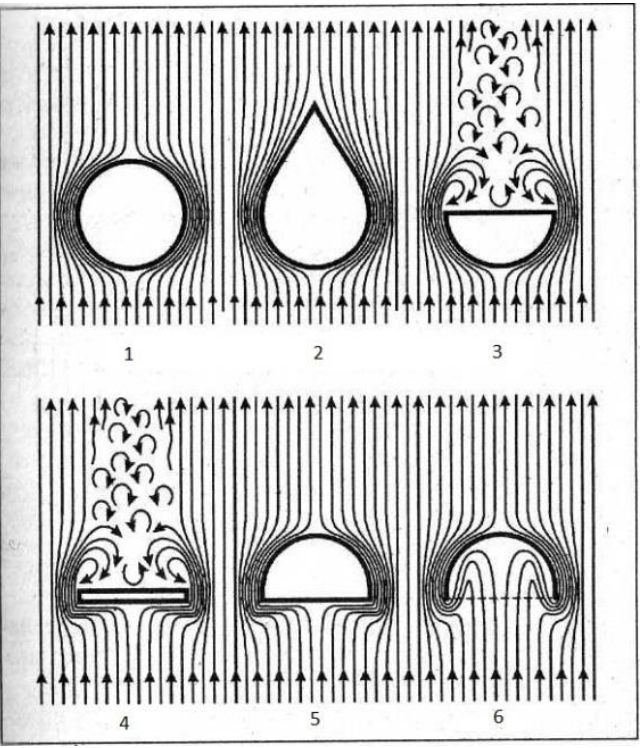

Fig. 8. Flow over particles of different shapes:

On the basis of the formulas analysis presented above (8-16), the hydraulic size can be represented as a function of several quantities:

$$
\omega=f\left(d, \rho_{\mathrm{T}}, \rho, F, C_{D}, k_{\rho}, \mu, \ldots\right)
$$

Analyzing how the diameter is taken into account in theoretical formulas (see formulas $8-16$ ), we can see that the hydraulic size is a linear function of $d$ (Allen), quadratic- $\mathrm{d}^{2}$ (Stokes), or the root of the diameter (Rettinger, Ruby, etc.) All experimental data presented on the resulting graph of the hydraulic size versus diameter (Fig. 9). X-axis - diameters (mm). Y-axis - particle velocity determined experimentally $(\mathrm{mm} / \mathrm{sec})$.

The graph also add approximations $\mathrm{y} \sim \mathrm{x} ; \mathrm{y} \sim 1.7 \cdot \mathrm{x} ; \mathrm{y} \sim \mathrm{x}^{2}$ and $\mathrm{y} \sim \mathrm{x}^{(1 / 2)}$ corresponding to the basic calculation formulas. The correspondence of experimental data to the basic approximations is presented in Table 3 . 


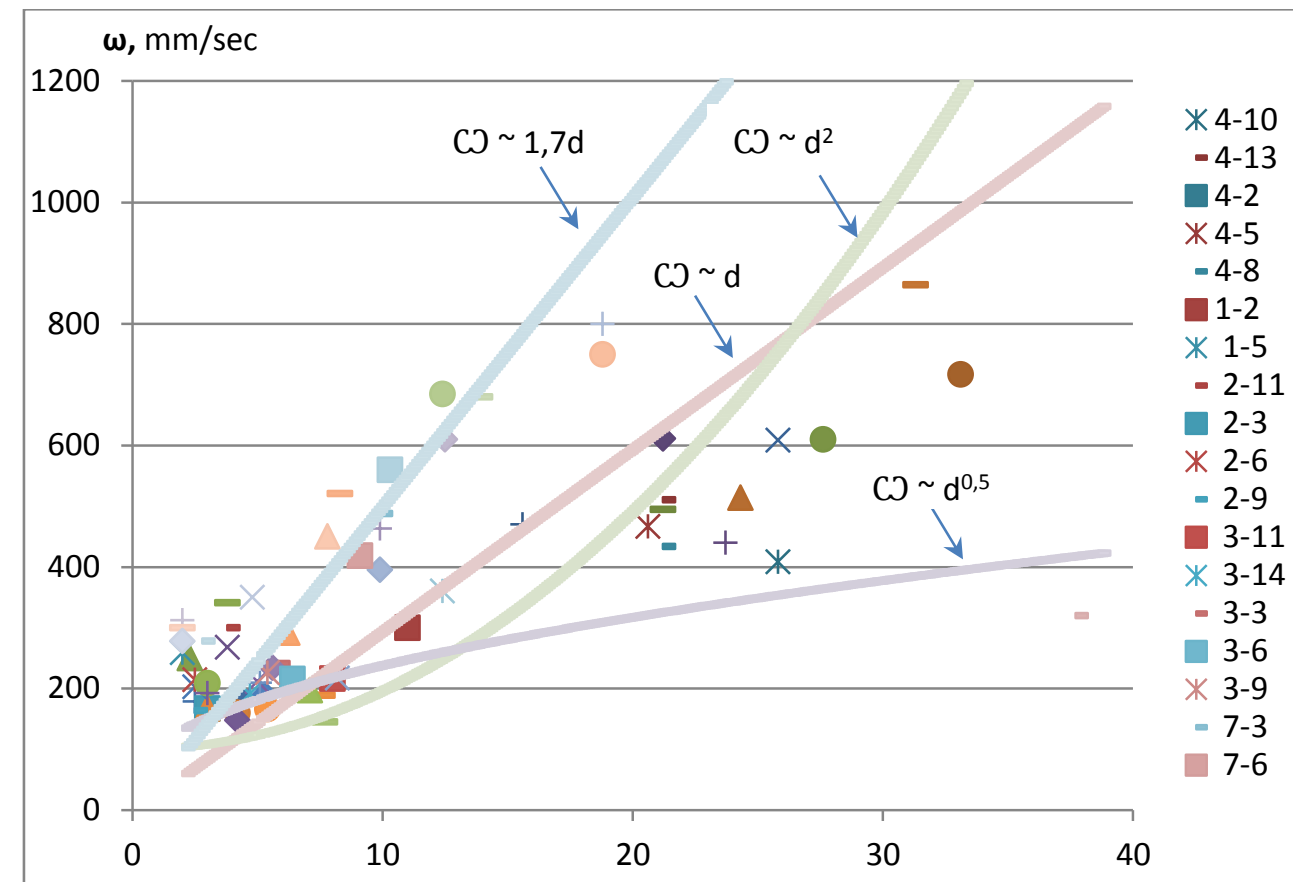

Fig. 9. Dependence of hydraulic size on diameter

Table 3. Analysis of experimental data

\begin{tabular}{|c|c|c|c|c|c|}
\hline Low & $\begin{array}{c}\text { For the all } \\
\text { experimental } \\
\text { base }\end{array}$ & $\begin{array}{c}\text { For solid } \\
\text { particles, } \\
\text { diameter } \\
10 \mathrm{MM}\end{array}$ & $\begin{array}{c}\text { For solid } \\
\text { particles, } \\
\text { diameter } \\
\text { from 10mm } \\
\text { to 20mm }\end{array}$ & $\begin{array}{c}\text { For solid } \\
\text { particles , } \\
\text { diameter }> \\
20 \mathrm{MM}\end{array}$ & $\begin{array}{c}\text { For solid } \\
\text { particles, } \\
\text { diameter }< \\
20 \mathrm{MM}\end{array}$ \\
\hline $\mathrm{y} \sim \mathrm{x}^{2}$ & $16,6 \%$ & $4,7 \%$ & $40,0 \%$ & $31,0 \%$ & $11,4 \%$ \\
\hline $\mathrm{y} \sim 1,7 \cdot \mathrm{x}$ & $15,7 \%$ & $18,7 \%$ & $33,0 \%$ & - & $21,5 \%$ \\
\hline $\mathrm{y} \sim \mathrm{x}^{(1 / 2)}$ & $50,9 \%$ & $71,8 \%$ & - & $31,0 \%$ & $58,2 \%$ \\
\hline $\mathrm{y} \sim \mathrm{x}^{2}$ & $16,8 \%$ & $4,8 \%$ & $27 \%$ & $38,0 \%$ & $8,9 \%$ \\
\hline
\end{tabular}

The closest approximations for particles with diameters less than $10 \mathrm{~mm}$ is $\mathrm{y} \sim \mathrm{x}^{(1 / 2)}$,

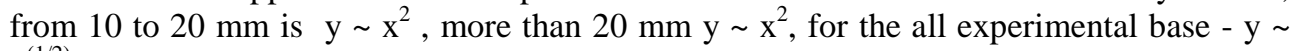
$\mathrm{x}^{(1 / 2)}$. So the root of the diameter is closest approximation. Analysis shows the smaller the particle, the higher the convergence with the experiment.

Figure 11 shows that the influence of the diameter on the hydraulic size decreases with its growth. The large variation of the hydraulic size values for close diameters indicates a significant influence of the shape on the particle velocity. This is due to the fact that the particle in the flow in addition to the translational motion also makes a rotational motion, orienting in the flow with the smallest cross-section.

\section{Conclusions}

At this stage, it is advisable to conclude that the hydraulic size for the non-spherical solid particles is proportional to the root of the diameter. The shape of the particle has a great 
influence on the velocity of its movement. Turbulent flow, in comparison with laminar flow, is characterized by the presence of velocity (and pressure) pulsations, including in the area around the solid particle. The mechanism of motion of a solid particle in a turbulent flow is different from the free fall of the particle in the field of gravity alone. The effect of turbulence on the velocity of the solid particle in the flow will be considered in further works.

The use of the hydraulic size in the movement of real two-phase flows (in canals and rivers) should be done with caution associated with the following methodological problems:

1). Hydraulic size is the rate of particle velocity in a stationary liquid, but a solid particle in a flow is the motion of a particle in a stream. The mechanisms in the flow are significantly different, and the hydraulic size does not take into account these differences.

2). The method of measurement of hydraulic size is aimed at measuring the velocity of only one particle, and the flow moves a number of particles. Therefore, the relative interaction between solid particles influence on the velocity hydraulic size.

\section{References}

1. A. Breugem, Transport of suspended particles in turbulent open channel flow (2012)

2. I. Studenov, N. Shilova, Arctica: ekologiya i ekonomika 3 p. 40-47 (2015)

3. L. Volgina, S. Sergeev, A. Romanova, Gidrotekhnicheskoe stroitelstvo № 10. p. 59-63 (2018)

4. L. Volgina, V. Tarasov, Vestnik MGSU 8 p.111-115 (2011)

5. L. Volgina, A. Romanova, Integratsiya, partnerstvo i innovatsii v stroitelnoy nauke $\mathrm{i}$ obrazovanii. Sbornik materialov VI Mezhdunarodnoy nauchnoy konferentsii, p.178-183 (2018)

6. V. Borovkov, F. Mayranovsky, Aerogidrodinamika sistem ventilyatsii $i$ konditsionirovaniya vozdukha p. 30-42 (1978)

7. A. Zuykov, L. Volgina, Gidravlika 2 (2014)

8. YU. Bryanskaya, I. Markova, A. Ostyakova, Gidravlika vodnykh i vzvesenesushchikh potokov $v$ zhestkikh i deformiruyemykh granitsakh (2009) 